\title{
Novel micropatterns mechanically control fibrotic reactions at the surface of silicone implants
}

\author{
Hicham Majd a, b, c, 1 , Saja S. Scherer ${ }^{\text {b, } 1}$, Stellar Boo ${ }^{\text {d, }}$, Silvio Ramondetti a, \\ Elizabeth Cambridge ${ }^{\mathrm{d}}$, Wassim Raffoul ${ }^{\mathrm{b}}$, Michael Friedrich ${ }^{\mathrm{c}}$, Brigitte Pittet ${ }^{\mathrm{e}}$, \\ Dominique Pioletti a, Boris Hinz ${ }^{\mathrm{d}, *, 1}$, Giorgio Pietramaggiori ${ }^{\text {b, }}{ }^{* *}, 1$ \\ a Biomechanical Orthopedics Laboratory, Ecole Polytechnique Fédérale de Lausanne, Switzerland \\ ${ }^{\mathrm{b}}$ Department of Plastic, Reconstructive and Aesthetic Surgery, University Hospitals of Lausanne, Switzerland \\ ${ }^{c}$ Laboratory of Cell Biophysics, Ecole Polytechnique Fédérale de Lausanne, Switzerland \\ ${ }^{\mathrm{d}}$ Laboratory of Tissue Repair and Regeneration, Matrix Dynamics Group, Faculty of Dentistry, University of Toronto, Canada \\ e Department of Plastic, Reconstructive and Aesthetic Surgery, University Hospitals and Faculty of Medicine of Geneva, Switzerland
}

\section{A R T I C L E I N F O}

\section{Article history:}

Received 25 November 2014

Received in revised form

6 March 2015

Accepted 15 March 2015

Available online

\section{Keywords:}

Fibrosis

Foreign body reaction

Myofibroblast

Collagen

Contracture

Mechanobiology

\begin{abstract}
A B S T R A C T
Over the past decade, various implantable devices have been developed to treat diseases that were previously difficult to manage such diabetes, chronic pain, and neurodegenerative disorders. However, translation of these novel technologies into clinical practice is often difficult because fibrotic encapsulation and/or rejection impairs device function after body implantation. Ideally, cells of the host tissue should perceive the surface of the implant being similar to the normal extracellular matrix. Here, we developed an innovative approach to provide implant surfaces with adhesive protein micropatterns. The patterns were designed to promote adhesion of fibroblasts and macrophages by simultaneously suppressing fibrogenic activation of both cell types. In a rat model, subcutaneously implanted silicone pads provided with the novel micropatterns caused 6-fold lower formation of inflammatory giant cells compared with clinical grade, uncoated, or collagen-coated silicone implants. We further show that micropatterning of implants resulted in 2-3-fold reduced numbers of pro-fibrotic myofibroblast by inhibiting their mechanical activation. Our novel approach allows controlled cell attachment to implant surfaces, representing a critical advance for enhanced biointegration of implantable medical devices.
\end{abstract}

() 2015 Elsevier Ltd. All rights reserved.

\section{Introduction}

The number of implanted medical devices such as pacemakers, glucose sensors, and joint replacements prosthesis is steadily increasing to address the needs of an aging population. These devices dramatically improved the life of millions of patients worldwide. However, in select applications such as diabetes and support

\footnotetext{
* Corresponding author. Laboratory of Tissue Repair and Regeneration, Matrix Dynamics Group, Faculty of Dentistry, Fitzgerald Building, Room 234, University of Toronto, 150 College Street, Toronto, Ontario M5S 3E2, Canada. Tel.: +1 416978 8728; fax: +1 4169785956 .

** Corresponding author. Plastic and Reconstructive Surgery, Centre Hospitalier Universitaire Vaudois Lausanne - CHUV, Rue du Bugnon 46, 1011 Lausanne, Switzerland.

E-mail addresses: boris.hinz@utoronto.ca (B. Hinz), gpietramaggiori@gmail.com (G. Pietramaggiori).

${ }^{1}$ The authors contributed equally to this study.
}

of the central nervous system, sensors for continuous monitoring and treatment of chronic conditions, clinical translation is complicated due to foreign body reactions [1-8]. Depending on the surface material, recipient site, and contact duration, implants induce fibrotic reactions that manifest clinically as scar-like capsules around the device [3]. Fibrotic encapsulation not only reduces the function and half-life of the device but can severely affect the functionality of the host tissue in critical situations such as infections, often requiring additional surgery for explantation, adding risks for the patients and increasing the costs for the health care system [9].

To improve implant device acceptance and function by reducing foreign body and fibrotic reactions, we need to understand the mechanisms of tissue-biomaterial interactions. Several parameters have been investigated to control foreign body reactions such as functionalization with growth factors [10]. However, including such biological clues in the implant material has not yet been sufficient 
to guide healing for a variety of reasons. First, the release of signaling molecules must follow a precisely controlled time and concentration course in order to avoid a paradoxical down regulation of specific receptors. Second, the biophysical properties of the material is a powerful factor controlling the behavior of cells such as terminal differentiation or activation, even overriding specific actions of growth factors. Since controlling the orchestrated expression of soluble molecules in vivo is a daunting if not impossible task to date, we set out to manipulate the biophysical properties of cell interactions with the extracellular matrix (ECM) to guide cell behavior on the biomaterial surface. Our strategy principally aims in controlling the activation of host-tissue resident mesenchymal cells into myofibroblasts in the peri-prosthetic wound.

Myofibroblasts are characterized by the neo-expression of $\alpha$ smooth muscle actin ( $\alpha$-SMA) and the excessive production of collagen. It is the incorporation of $\alpha$-SMA into microfilament bundles (stress fibers) that confers high cell contractile activity [11]. Myofibroblast forces are transmitted to and perceived from the ECM at sites of large, "supermature" focal adhesions (FA) that are termed 'fibronexus' in vivo [12-15]. FA mechanosensing is the basis for spontaneous myofibroblast activation upon adhesion to sufficiently rigid surfaces [11]. Since abnormal interaction of fibroblasts with implant surfaces is a possible major cause for the development of implant encapsulation, a variety of specific surface coatings have been developed to improve biointegration $[3,16]$, such as adding Arg-Gly-Asp (RGD) sequences to mimic the integrin signaling domain of fibronectin. However, we hypothesize that the specific size and distribution of the adhesion sites - rather than their sheer presence in the substrate itself - is the key aspect to guide cell attachment and behavior.

Using fibroblast culture models, we have previously shown that the size of FAs is directly proportional to the level of intracellular tension and the activation state of myofibroblasts. Formation of too small FAs prevents fibroblasts to attach and survive, formation of too large FAs translates into excessive tension development and ultimately myofibroblast activation [17]. Here, we identified specific anti-fibrotic protein micro-patterns and transferred them onto silicone polymer surfaces in order to modulate cell-implant interactions. To stably transfer cell-adhesive proteins with micrometer resolution onto compliant silicone substrates, we developed an innovative stencil technology. Proteins are deposited in the desired pattern through the openings of a stencil, produced by photolithography. The principle of our novel implant surface coating procedure is applicable to most implant materials and shapes and we demonstrate that it is effective to suppress myofibroblast and inflammatory cell activation at the surface of silicone implants in cell culture and animal experiments.

\section{Materials and methods}

\subsection{Cell culture and reagents}

Primary rat fibroblasts were explanted from subcutaneous tissue and used between passages P2 and P5 as described before [18] and cultured in standard Dulbecco's modified Eagle's medium (DMEM; Life Technologies), supplemented with $10 \%$ fetal bovine serum (Sigma-Aldrich), and penicillin/streptomycin (Life Technologies). Myofibroblast activation was induced using $2 \mathrm{ng} / \mathrm{ml}$ TGF- $\beta 1$ (R\&D Systems, Abington, UK) added once for 5 days to the culture medium. Murine lineage RAW 264.7 macrophages were cultured in standard medium and culture dishes. Macrophages were activated by adding LPS for 7 days to cells grown on coated/ uncoated silicone substrates.

\subsection{Hard stencil production}

To create a 'hard microstencil' silicon mask, exhibiting arrays of openings with characteristics of FAs at the bottom of a micro-reservoir, we used a silicon-oninsulator (SOI) 380-2-50 wafer, dry etching, and soft lithography (Fig. 1a). Briefly, SOI wafer with the following dimensions have been used: upper silicon layer of $10 \mu \mathrm{m}$ thickness, silicon oxide of $1 \mu \mathrm{m}$ thickness and a lower silicon layer of $380 \mu \mathrm{m}$ thickness. After cleaning the SOI with piranha solution, a $2 \mu \mathrm{m}$ layer of oxide was grown by wet oxidation. This layer served as a reinforcement mask for the photoresist during the etching processes. To create the microstructure bottom side of the stencil we used a mask with small dimension holes and a $3 \mu \mathrm{m}$ layer of AZ9260 photoresist. The mask pattern was transferred to the photoresist in a classical photolithography step. To achieve a high aspect ratio for the holes, which was recognized to be important for protein transfer, we applied an advanced dry etching Bosch process. After etching, the photoresist was removed and the wafer was turned to continue with the upper side's processing to generate the stencil reservoir. A second photolithography step was then applied, using a $10 \mu \mathrm{m}$ layer of the photoresist AZ9260 and a second mask to produce the wide opening of the reservoir. Dry etching was again used to first remove the silicon oxide and second to etch through the thick silicon layer down to the interior oxide layer, serving to stop the etching process. Finally, photoresist and oxide layer were removed using a wet etching process to generate microstructure openings.

\subsection{Pliable stencil production}

To transfer proteins to curved surfaces that excluded close contact with the hard stencil, we developed an alternative method to create 'soft microstencils' (Fig. 1b). Briefly, plasma oxygen cleaned silicon wafers were used as support to deposit a $10 \mu \mathrm{m}$ thick layer of parylene $\mathrm{C}$ using a parylene deposition system (Comelec C-30-S, La Chaux-de-Fonds, Switzerland). A second layer of $500 \mathrm{~nm}$ amorphous silicon (a-Si) was deposed using a sputter (Pfeiffer SPIDER 600, Zürich, Switzerland), serving as support for photoresist spin-coating. A photolithography step using a mask with small dimension holes was then applied to $1 \mu \mathrm{m}$ photoresist S1805. After development of the photoresist, we applied a dry etching of a-Si layer using a silicon etcher (Alcatel AMS 200 SE, Annecy, France) and dry etching Parylene C using (STS Multiplex ICP). As terminal step, a-Si was stripped.

\subsection{Silicone implants and protein deposition}

Silicone pads consisting of clinical grade silicone (Silbione LSR4305, Silitech SA, Gümligen, Germany) with dimensions $10 \times 10 \times 1 \mathrm{~mm}$ were either left uncoated (control, corresponding to clinically used silicones) or covalently coated with collagen type I (100 $\mu \mathrm{g} / \mathrm{ml}$, Devro Medical LTD, Glascow, UK), or human plasma fibronectin (FN, Sigma). To provide surfaces with a non-protein adhesive molecule, we used poly N-acetyl glucosamine (sNAG, Marine Polymer Technologies, Inc. Burlington, MA, USA). For complete coating, collagen, FN, and sNAG were covalently bound to silicone substrates, in consequent treatments with plasma oxygen, 3aminopropyltriethoxysilane (APTES) and glutaraldehyde [19,20] (Fig. 1c). In brief, silicone surfaces were pre-treated with plasma oxygen (100 W, 300 mTorr, $45 \mathrm{~s}$ ) (Tepla, Kirchheim, Germany). This layer was then covalently provided with amine groups by incubation with APTES (Sigma) ( $1 \%$ in water) and subsequent heating to $60{ }^{\circ} \mathrm{C}$ for $60 \mathrm{~min}$. Substrates were then copiously washed with PBS, immersed with $0.1 \%$ glutaraldehyde for $20 \mathrm{~min}$, washed again 3-times with PBS and covalently crosslinked with collagen for $60 \mathrm{~min}$ at $37^{\circ} \mathrm{C}$ [20]. For patterning, we exposed the silicone surface to the same protein/sNAG functionalization procedure through a silicon microstencil, exhibiting arrays of openings on the bottom of a microreservoir with dimensions $2 \times 2,4 \times 2,6 \times 2,8 \times 2,10 \times 2$, and $20 \times 2 \mu \mathrm{m}$, and regular spacing of $5 \mu \mathrm{m}$. The stencil was removed to leaving the protein patterned silicone (Fig. 1c). In one series of experiments, we used polycarbonate filters (Merck Millipore, Tullagreen, Ireland) exhibiting pores with diameters of 2, 5 and $10 \mu \mathrm{m}$ to produce irregular patterns of adhesive islands. All protein-coated surfaces were treated with PLL-g-PEG to prevent cell attachment any non-protein-coated regions (passivation) as described before [17].

\subsection{Antibodies, microscopy, and image analysis}

For immunofluorescence, we used primary antibodies directed against $\alpha$-SMA ( $\alpha$ SM-1, a gift from Dr. G. Gabbiani, University of Geneva, CH), FN (Sigma), collagen type I (Acris, San Diego, CA), F4/80 (BioLegend, San Diego, CA), CD68 (Abcam, Cambridge, MA), and vinculin (hVin-1, Sigma). Primary antibodies were probed with AlexaFluor-conjugated goat anti-mouse, goat anti-rat, and goat anti-rabbit secondary antibodies (Molecular Probes, Invitrogen, Basel, $\mathrm{CH}$ ). DNA was probed with DAPI (Sigma) and F-actin with Phalloidin-Alexa 488 (Molecular Probes) [21]. Phase contrast and epifluorescence microscopy was performed using oil immersion objectives (Plan-Neofluar 40x/1.2 Ph3, Plan-Neofluar 63x/1.4 Ph3, Zeiss) mounted on an inverted microscope (Axiovert 135, Carl Zeiss AG, Feldbach, $\mathrm{CH}$ ) and digital CCD camera (Hamamatsu C4742-95-12ERG, Bucher Biotec AG, Basel, CH). Images were acquired with Openlab 3.1.2 software (Improvision, Basel, $\mathrm{CH}$ ) and assembled with Adobe Photoshop CS5. To quantify the level of myofibroblast activation, the percentages of $\alpha$-SMA stress fiber-positive cells of all cells were quantified in a semiautomated algorithm in Image J (U. S. National Institutes of Health (NIH), Bethesda, Maryland, USA, http://imagej.nih.gov/ij/, 1997-2013). Macrophage fusion into multi-nucleated giant cells was quantified by automatically detecting the number of nuclei within the boundaries of F4/80-positive single cells. To exclude that aggregates are quantified as single cells, macrophages were detached after 7 day growth on silicone surfaces, mechanically separated and reseeded onto standard plastic dishes to be quantified after another $6 \mathrm{~h}$. Mean values \pm standard deviation 
a Hard silicon stencil

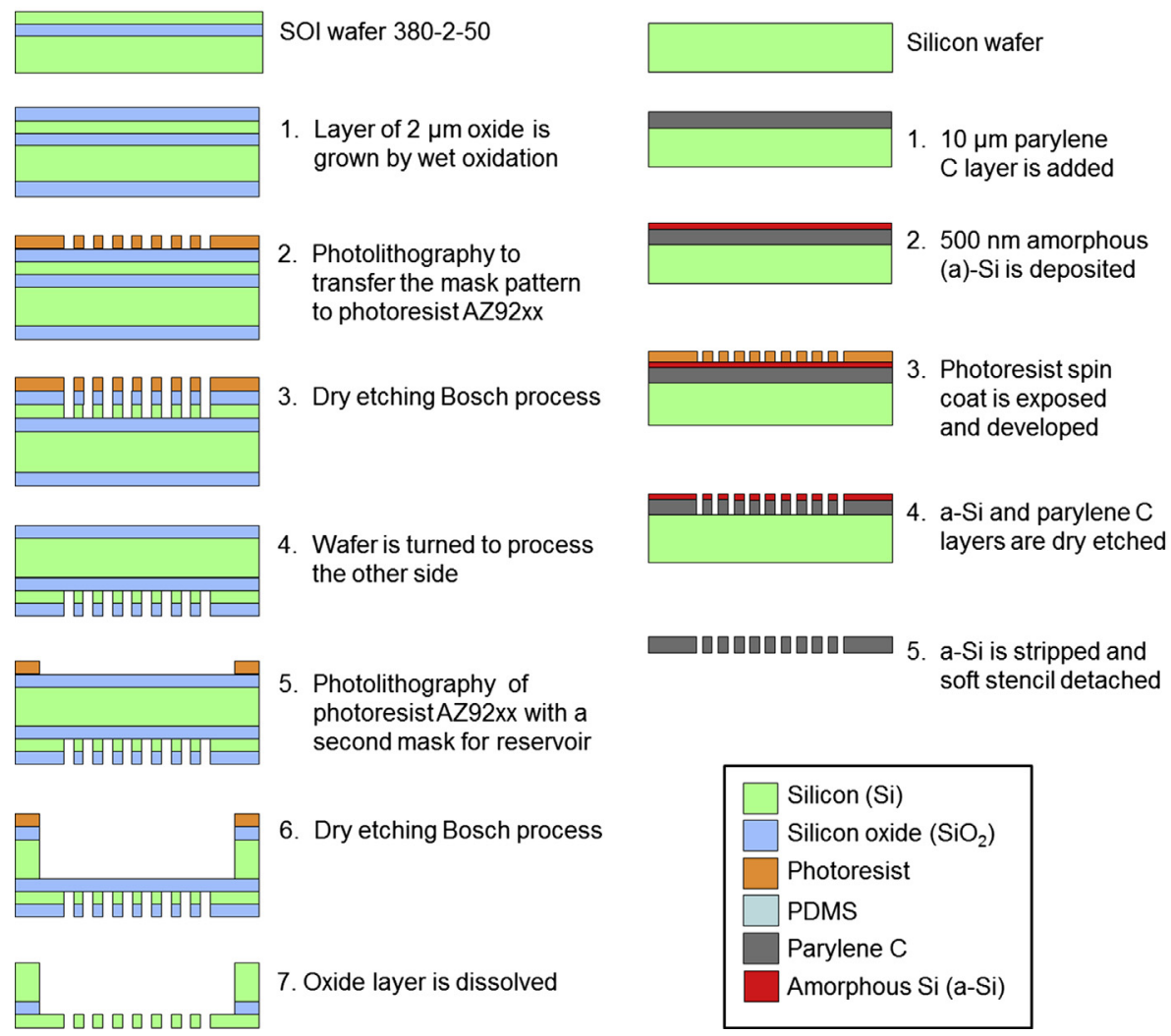

\section{PDMS functionalization}

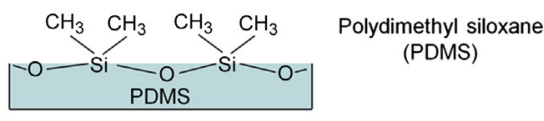

1. Hydroxylize with plasma oxygen treatment

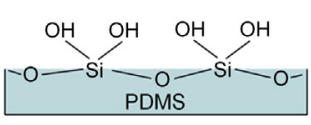

2. Silanize with (3-Aminopropyl) triethoxysilane (APTES)

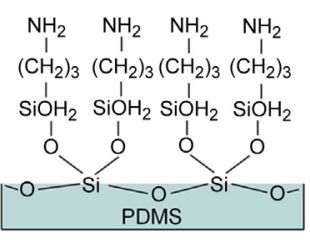

$\mathrm{Si}(\mathrm{OH})_{3}\left(\mathrm{CH}_{2}\right)_{3} \mathrm{NH}_{2}$

3. Glutaraldehyde, followed by collagen addition

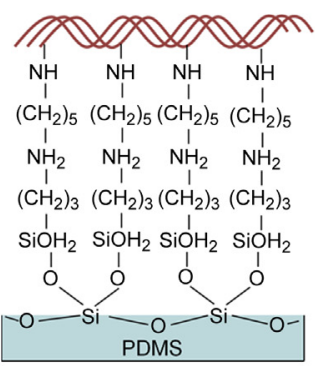

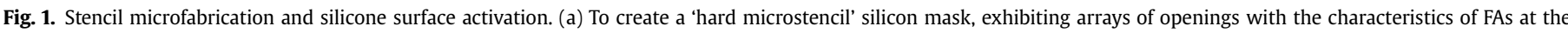

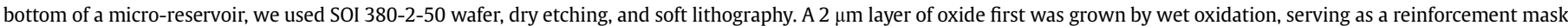

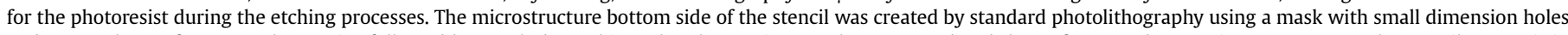

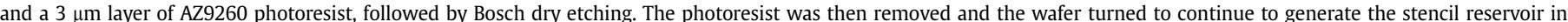

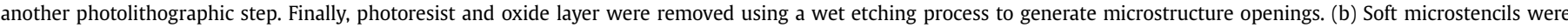

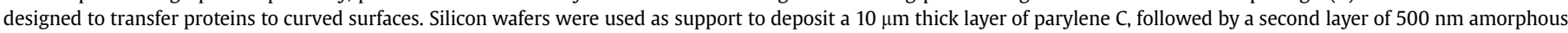

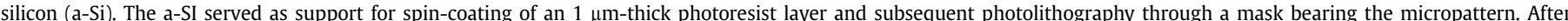

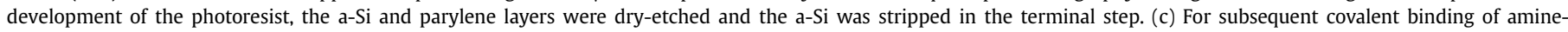
containing molecules (e.g., proteins and sNAG), silicone substrates were functionalized in consequent treatments using plasma oxygen, APTES and glutaraldehyde.

(SD) were calculated from at least three independent experiments, each comprising ten random regions of interest per experimental condition ( 100 cells/field).

\subsection{Animal surgery and analysis of fibrotic capsules}

Adult male Wistar strain rats $(300-400 \mathrm{~g})(\mathrm{n}=20)$ were fed a standard RM1 diet (Nordos, Val de Reuil, France) and given water ad libitum. Each animal was subcutaneously implanted in the dorsal region with two uncoated implants, one completely collagen coated implant, and one implant coated with arrays of $4 \times 2 \mu \mathrm{m}$ islands, spaced $5 \mu \mathrm{m}$. The dimensions of the implants were $10 \times 10 \times 1 \mathrm{~mm}$. Positions were randomly allocated and shifted in different animals on the dorsum of the animals. After 30 days with the implant, rats were euthanized by carbon dioxide after isoflurane anesthesia. The local ethics committee and veterinary authority approved all procedures in accordance with Swiss guidelines. Implants were excised in block with the surrounding tissue. Tissue samples were fixed in $10 \%$ neutralbuffered formalin, embedded in paraffin, sectioned, and stained with hematoxylin and eosin (H\&E) for histological analysis (Poly Scientific, Bay Shore, NY). For immunofluorescence staining of rat tissue, sections were deparaffinized in xylene, rehydrated in ethanol, and rinsed in distilled water. Antigens were revealed by boiling the slides in sodium citrate buffer (Dako, Burlington, ON) at 95-100 C for $40 \mathrm{~min}$. After cooling to room temperature, sections were rinsed in PBS, blocked with $2 \%$ goat serum $/ 1 \%$ BSA for 40 min and stained with primary and secondary antibodies.

The accumulation of multi-nucleated foreign body giant foam cells was quantified in the central zone of the capsule on basis of $\mathrm{H} \& \mathrm{E}$ histological staining. Masson's Trichrome staining was performed on paraffin-embedded sections to stain for collagen. Myofibroblasts were identified by staining for $\alpha$-SMA as previously described [22]. Briefly, biotinylated $\alpha$-SMA antibody (R\&D Systems, Minneapolis, $\mathrm{MN}$ ) was applied to slides and incubated overnight at $4{ }^{\circ} \mathrm{C}$. Activation was performed with diaminobenzidine chromogen (DAB, Dako North America Inc., Carpinteria, CA) and counterstained with H\&E. Total (Masson's Trichrome) and $\alpha$-SMA positive capsule thickness were quantified using image analysis (Morpho-Expert, ExploraNova, La Rochelle, France) on three different areas of the capsule from the implant interface. Regions positive for collagen (blue in Trichrome Masson's staining) or for myofibroblasts (brown in $\alpha$-SMA staining) were calculated as a percentage of the whole area using Image $\mathrm{J}$.

\section{Results}

\subsection{Production of stencils with FA microstructure and protein deposition}

Previously, we suppressed myofibroblast activation on cell culture plastic and glass surfaces by restricting the length of FAs to $\leq 6 \mu \mathrm{m}$, using microprinting arrays of ECM protein islets [17]. Because microprinting of proteins is not efficient for softer silicone surfaces, e.g., such used in mammary implants, we developed a novel micro-stencil technique to generate and covalently link protein islets exhibiting FA features with lengths of 2, 4, 6, 8, 10, and $20 \mu \mathrm{m}$ and width of $2 \mu \mathrm{m}$ (Fig. 1). Using photolithography, hard silicon stencils were produced with arrays of openings in the desired dimensions and spacing of $5 \mu \mathrm{m}$ at the bottom of a reservoir (Figs. 1a, 2a-f). Pliable pyrelene stencils with the same array features were developed to apply patterns to strongly curved substrate surfaces (Figs. 1b, 2g-i). Both processes delivered stencils with 
openings having straight vertical borders down to the $2 \mu \mathrm{m}$ resolution (Fig. 2d-f, h-i).

To transfer proteins or the non-protein adhesive molecule sNAG, stencils were brought into conformal contact with silicone substrates and the stencil reservoir filled with protein/sNAG solution (Fig. 3a). In a series of preliminary experiments, we determined that silicone surface functionalization for covalent binding of protein and sNAG in consequent treatments with plasma oxygen, APTES, and glutaraildehyde $[19,20]$ was pivotal for long-term stability of the coat (Fig. 1c). After removing the stencil, non-printed regions of the hydrophobic silicone were additionally passivated against cell attachment by immersing the substrate in proteinrepellent PLL-g-PEG [17]. The resulting patterns of fluorescently labeled deposited FN (Fig. 3b, c), collagen type I and sNAG (Fig. 3c) accurately reproduced the printed structure. Primary rat subcutaneous fibroblasts formed vinculin-positive FAs specifically and exclusively where FN, collagen type I, and sNAG were stenciled onto the silicone in arrays of $4 \times 2 \mu \mathrm{m}$ and $20 \times 2 \mu \mathrm{m}$ islets (Fig. 3c). Identical results were obtained using pliable pyrelene stencils (unpublished data). FA formation of fibroblasts was impaired by growth on uncoated and extensive on completely coated silicones (Fig. 3c).
3.2. Microarrays of protein islands promote fibroblast adhesion to silicone and control phenotype

We next tested the efficacy of fibroblast adhesion to silicone sample strips, stenciled with adhesion island arrays. All FN-stenciled surfaces promoted attachment of fibroblasts in the absence (Supplementary Fig. S1) and presence of fibroblast-activating, profibrotic TGF- $\beta 1$ (Fig. 4a). Poor adhesion and cell spreading was observed on uncoated silicone (Fig. 4a, Supplementary Fig. S1). Quantifying the number of adherent fibroblasts after 5 days (initial seeding density: 75 cells $/ \mathrm{mm}^{2}$ ) demonstrated that arrays of $4 \times 2 \mu \mathrm{m}$ FN islands were most efficient to promote attachment and growth $\left(266 \pm 21\right.$ cells $\left./ \mathrm{mm}^{2}\right)$ (Fig. 4b). Adhesion was significantly higher compared with control substrates that were completely coated with FN $\left(176 \pm 16\right.$ cells $\left./ \mathrm{mm}^{2}\right)$. This attachment efficacy was similar on FN islets with dimensions $10 \times 2 \mu \mathrm{m}\left(196 \pm 5\right.$ cells $\left./ \mathrm{mm}^{2}\right)$ and $20 \times 2 \mu \mathrm{m}$ $\left(210 \pm 22\right.$ cells $/ \mathrm{mm}^{2}$ ) (Fig. 4 b). Cell numbers on $2 \times 2 \mu \mathrm{m}$ islet arrays $\left(85 \pm 3\right.$ cells $/ \mathrm{mm}^{2}$ ) were low and comparable to those on uncoated silicone substrates $\left(106 \pm 7\right.$ cells $\left./ \mathrm{mm}^{2}\right)$. On uncoated silicone substrates, fibroblasts did not spread, remained spherical, and tended to form aggregates that lifted off during the immunostaining procedure (Fig. 4a, Supplementary Fig. S1).
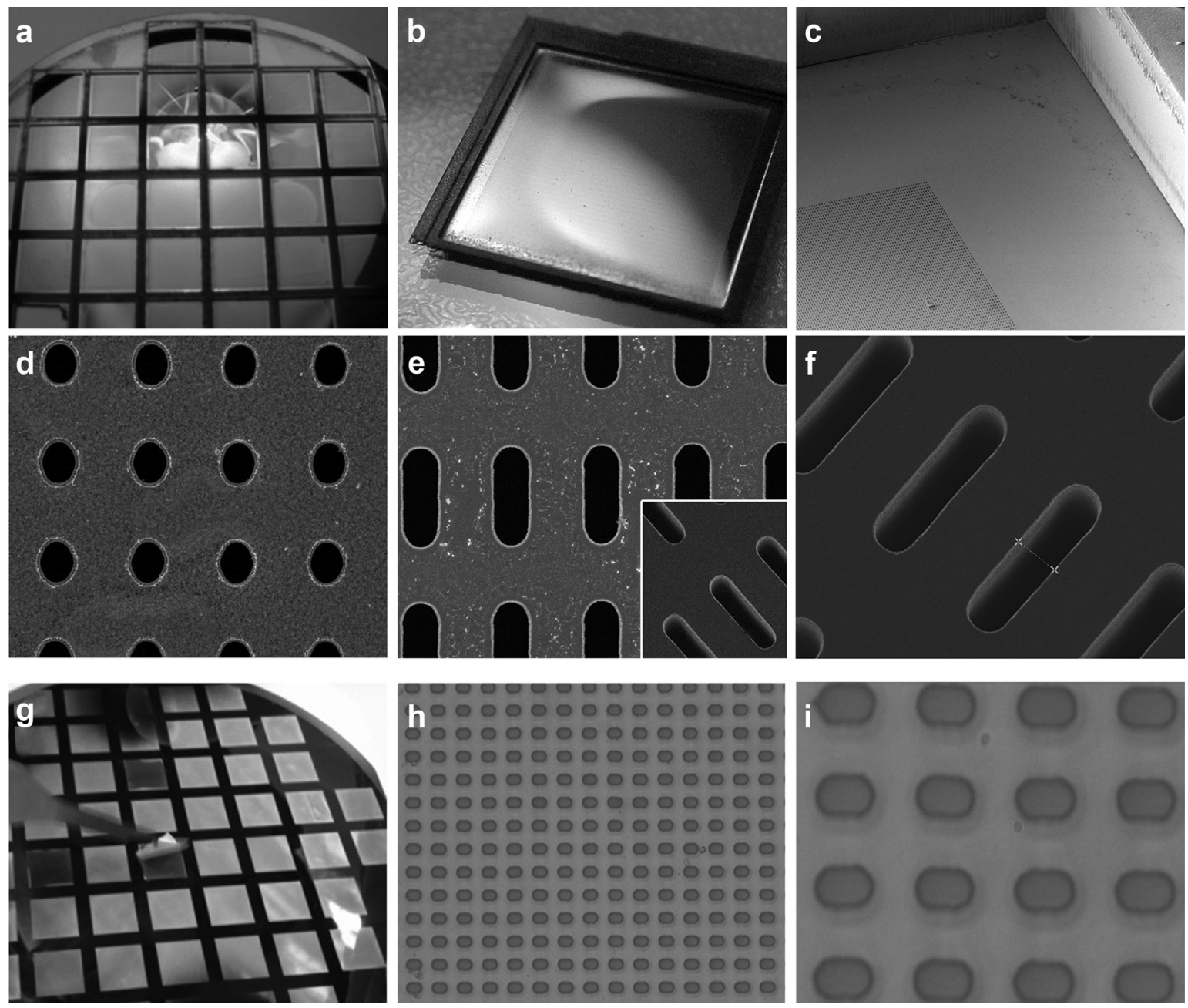

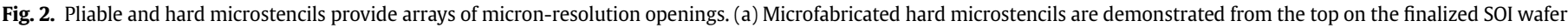

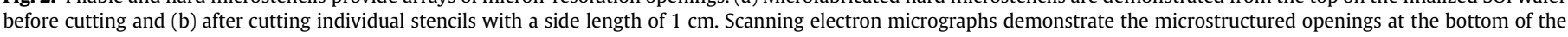

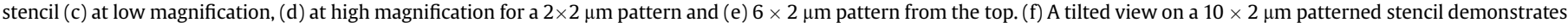

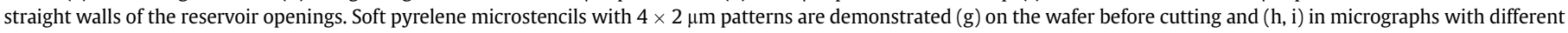
magnifications. 
a
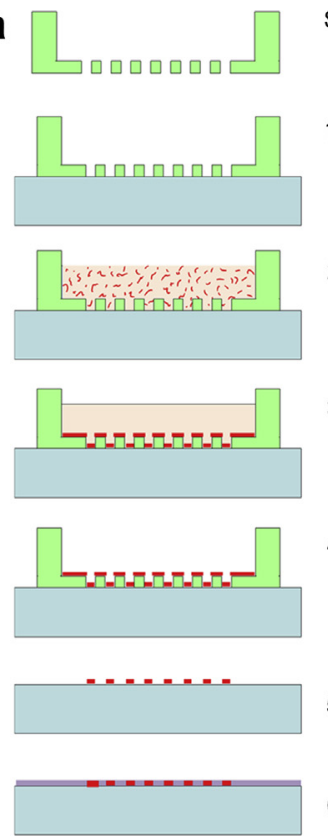

6. Passivate with PLL-g-PEG
3. Precipitate proteins/sNAG
4. Aspirate protein/sNAG solution coating remains
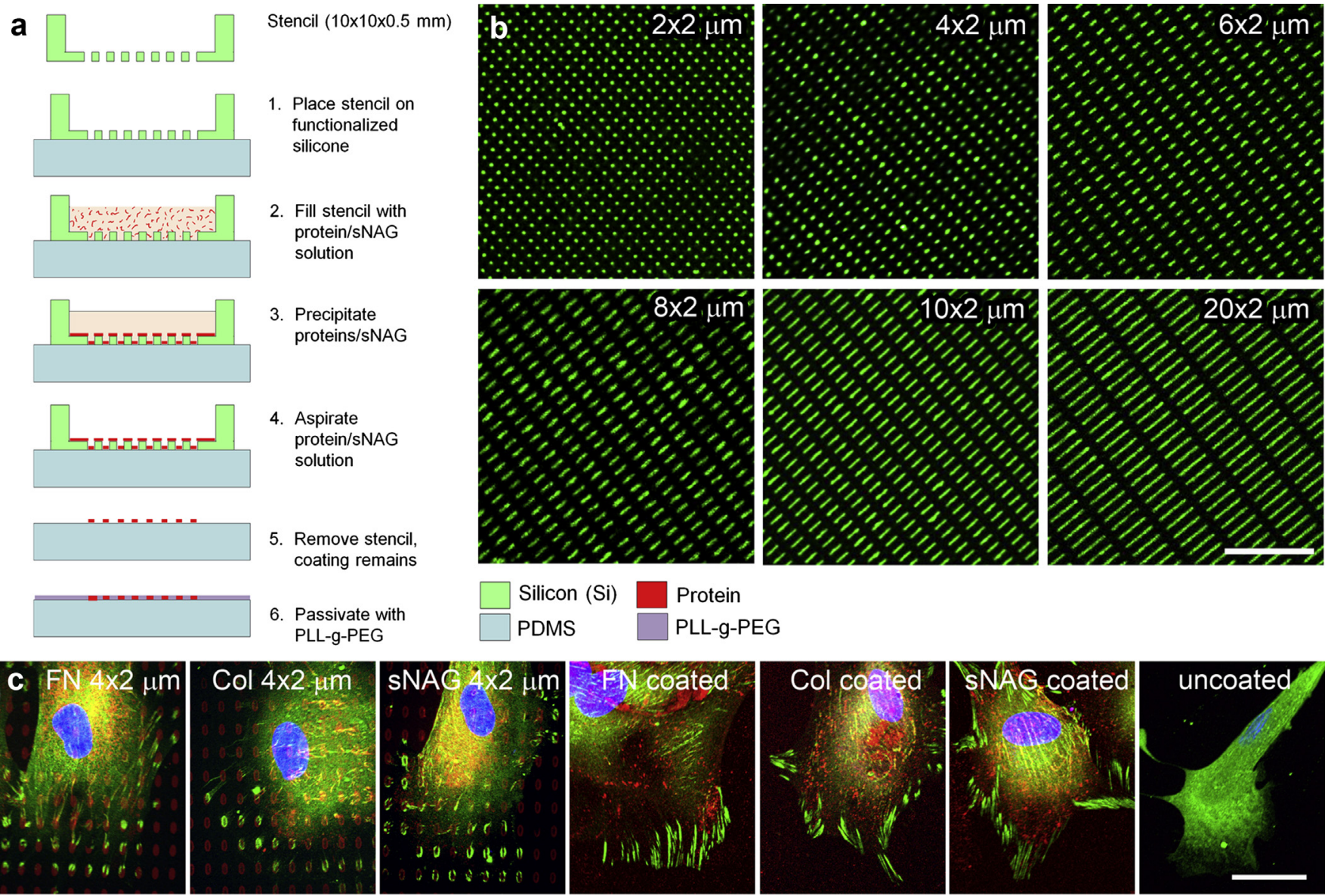

PDS
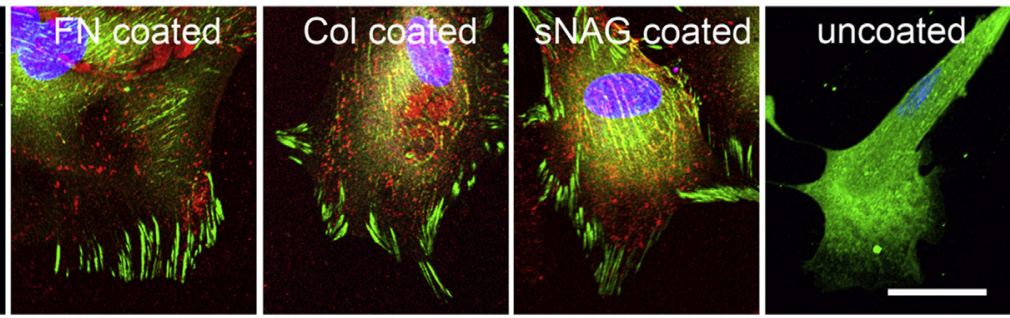

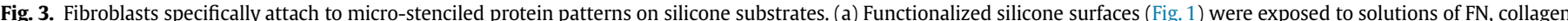

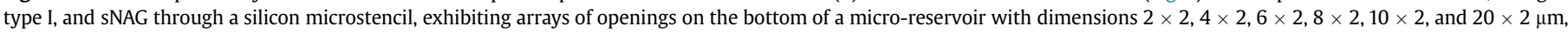

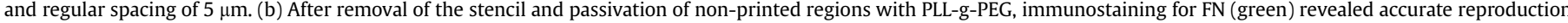

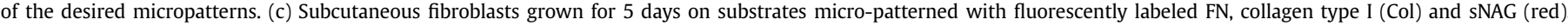

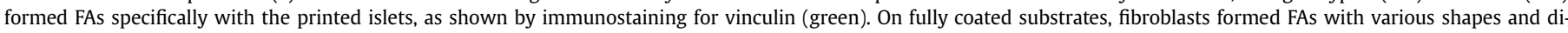

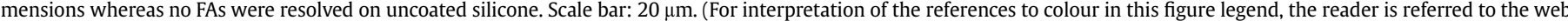
version of this article.)

To assess the effect of silicone micropatterning on fibroblast-tomyofibroblast activation, we quantified the percentage of rat subcutaneous fibroblasts expressing $\alpha$-SMA in stress fibers from immunofluorescence images (Fig. 4a). On silicone strips with complete FN coating, spontaneous myofibroblast activation was 14\% (Supplementary Fig. S1, Fig. 4c). This fraction was significantly lower on $2 \times 2 \mu \mathrm{m}$ and $4 \times 4 \mu \mathrm{m}$ islet arrays ( 2 -fold) and uncoated substrates ( $\sim 3$-fold), and was similar on $10 \times 10 \mu \mathrm{m}$ and $20 \times 20 \mu \mathrm{m}$ patterns (Supplementary Fig. S1, Fig. 4c). Notably, formation of $\alpha$ SMA-negative stress fibers was also reduced in cells grown on $2 \times 2 \mu \mathrm{m}$ patterns and stress fibers were completely absent from spherical cells on uncoated substrates (Supplementary Fig. S1). The surface of silicone implants after surgery is exposed to an inflammatory environment containing high levels of circulating cellderived TGF- $\beta 1$ [23]. Addition of TGF- $\beta 1$ for $5 d$ to the culture medium decreased cell numbers by $\sim 15 \%$ compared to the respective substrate condition in the absence of TGF- $\beta 1$ (unpublished data). TGF- $\beta 1$ induced an $\sim 4$-fold increase of the percentage of $\alpha$-SMApositive cells on completely coated silicone, $10 \times 2 \mu \mathrm{m}$, and $20 \times 2 \mu \mathrm{m}$ micropatterns ( 60\% $\alpha$-SMA stress fiber-positive cells) compared with TGF- $\beta 1$-free medium (Fig. $4 a, c)$. However, addition of TGF- $\beta 1$ only moderately increased the percentage of $\alpha$-SMA stress fiber-positive cells on $2 \times 2 \mu \mathrm{m}(\sim 20 \%)$ and $4 \times 2 \mu \mathrm{m}(\sim 30 \%)$ micropatterns (Fig. 4a, c). Coatings produced with collagen type I and sNAG delivered similar results than FN-coated substrates with respect to cell numbers (Fig. 4d) and percentage of $\alpha$-SMA-positive cells (Fig. 4e).

To control whether systematic arrangement and shaping of adhesive islets are required to affect fibroblast adhesion and myofibroblast activation, we next produced irregular patterns of similarly sized adhesive features. Silicone was stenciled with FN, collagen, and SNAG through polycarbonate filters exhibiting randomly arranged pores with diameters of 2, 5 and $10 \mu \mathrm{m}$ (Fig. 5a). Fibroblasts effectively attached and spread by forming FAs with the protein islets and were activated by TGF- $\beta 1$ to become $\alpha$-SMApositive myofibroblasts ( $60 \%)$ even on small islet patterns (Fig. 5b-d). Collectively, these data demonstrate that regular arrays of $4 \times 2 \mu \mathrm{m}$ adhesive islands allow for fibroblast attachment and proliferation by simultaneously suppressing $\alpha$-SMA organization into contractile fibers. This effect was not achieved using uncoated substrates that were found to be non-adhesive, and larger microarrays and completely coated substrates that lead to substantial myofibroblast activation.

\subsection{Microarrays of protein islets suppress monocyte/macrophage fusion into giant foam cells}

Foreign body reactions to silicone implants are initiated by the recruitment and activation of macrophages to the implant surface. One characteristic of an active inflammatory response and 

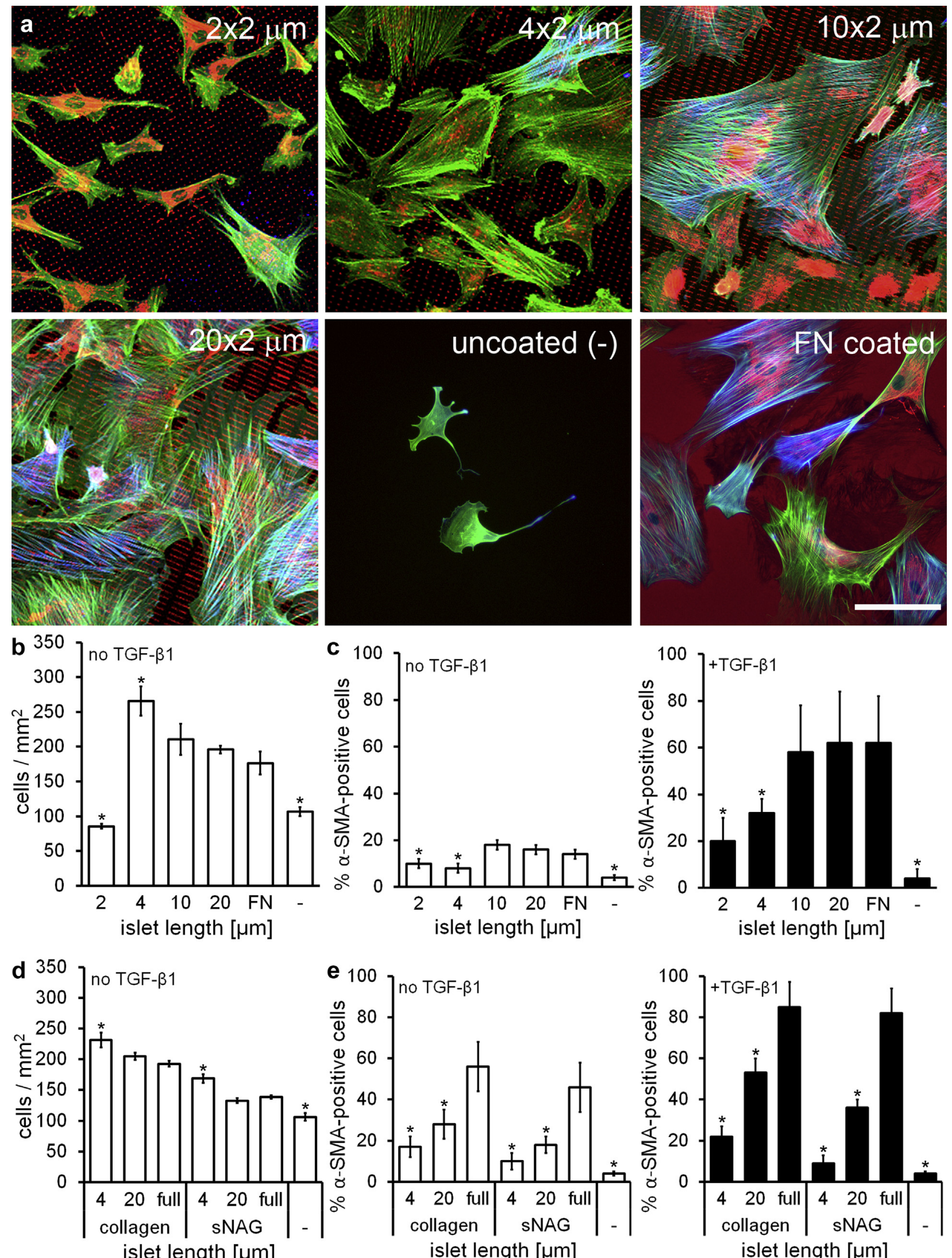

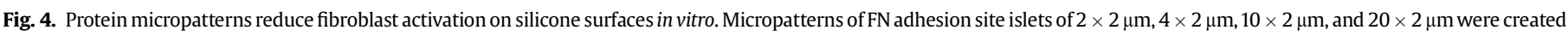

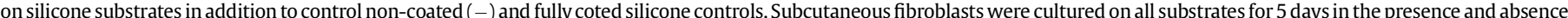

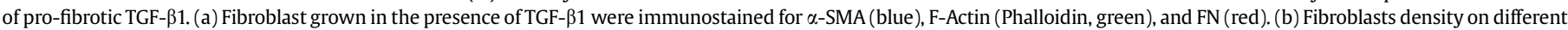

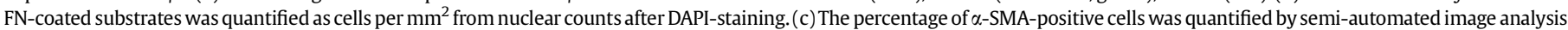

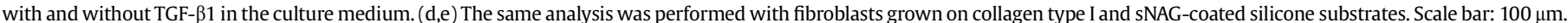

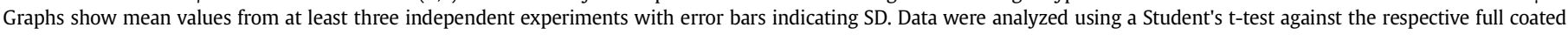
condition and statistical significance is indicated with ${ }^{*}=\mathrm{p}<0.01$. 

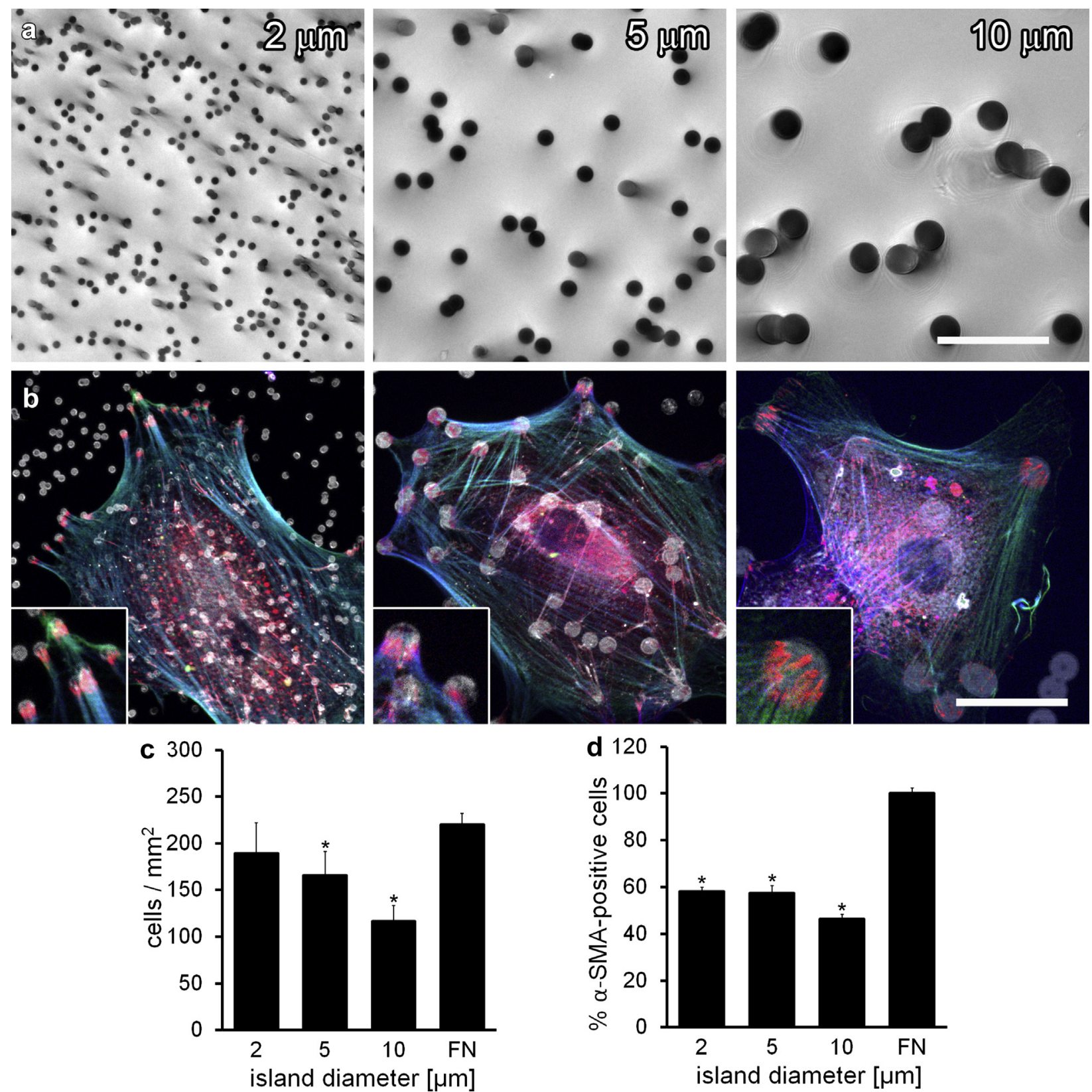

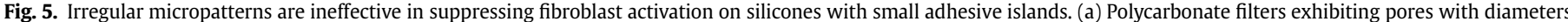

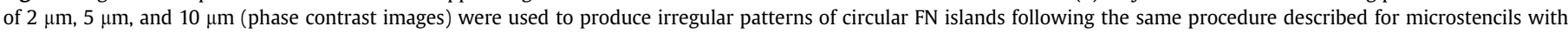

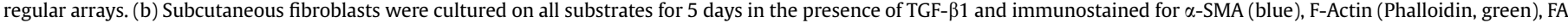

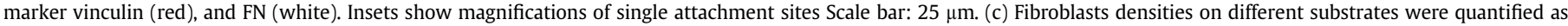

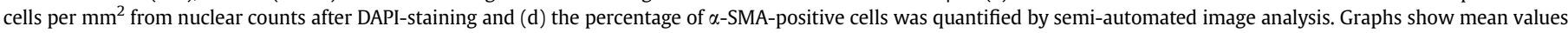

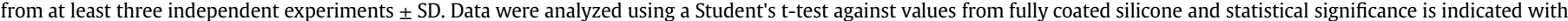
${ }^{*}=\mathrm{p}<0.01$. (For interpretation of the references to colour in this figure legend, the reader is referred to the web version of this article.)

precondition for the development of fibrosis is fusion of monocytes/macrophages into giant multi-nucleated cells during the foreign body reaction $[24,25]$. To evaluate the effect of micropatterns on macrophage activation, we seeded F4/80-positive murine macrophages onto uncoated, fully coated, and $4 \times 2 \mu \mathrm{m}$ FN pattern-coated silicone strips for 7 days in the presence of lipopolysaccharide (LPS). In contrast to fibroblastic cells, macrophages did not form discrete vinculin-positive FAs (unpublished data). Macrophages adhered with 2-fold higher numbers to fully FN coated $\left(387 \pm 15\right.$ nuclei $\left./ \mathrm{mm}^{2}\right)$ and uncoated silicone substrates $\left(453 \pm 18\right.$ nuclei $\left./ \mathrm{mm}^{2}\right)$ compared with $4 \times 2 \mu \mathrm{m}$ micro-patterned surfaces $\left(220 \pm 17\right.$ nuclei $\left./ \mathrm{mm}^{2}\right)$ (Fig. 6a, b). Formation of multinuclear giant foam cells was highest on full FN-coated silicone (86 $\pm 3 \%$ multi-nucleated cells) and lowest on micro-patterned silicone ( $20 \pm 4 \%$ multi-nucleated cells) (Fig. 6a, c). No differences were observed between FN and collagen coating (unpublished data).

\subsection{Implant micropatterns reduce foreign body reactions and} fibrotic capsule formation in vivo

Micropatterns of $4 \times 2 \mu \mathrm{m}$ islets of collagen, FN, and sNAG all promoted adhesion of cultured fibroblasts to silicone substrates and suppressed myofibroblast and macrophage activation. To 

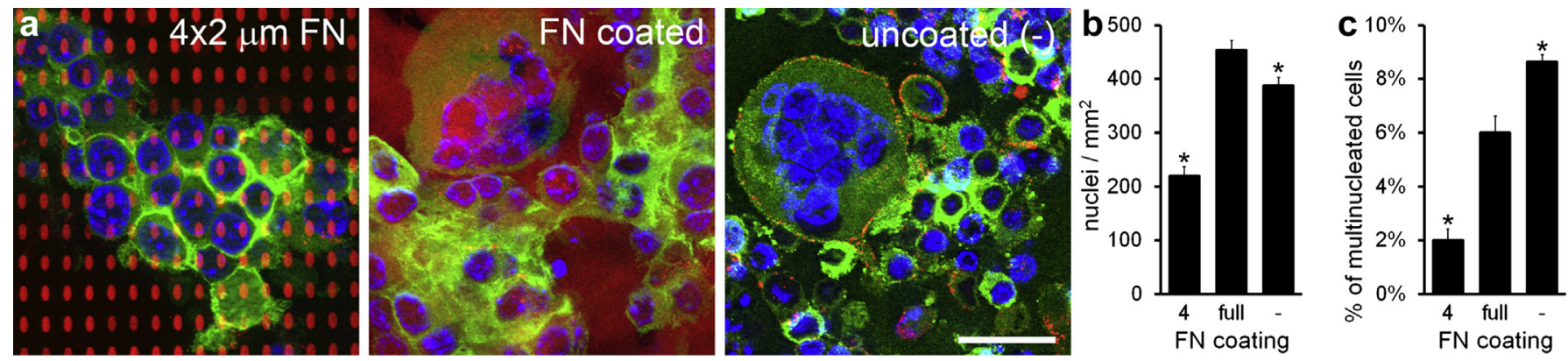

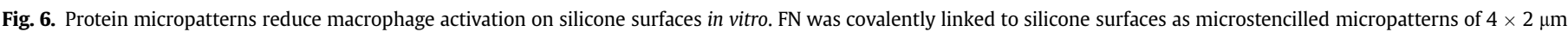

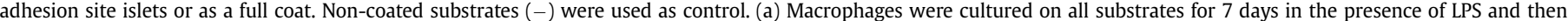

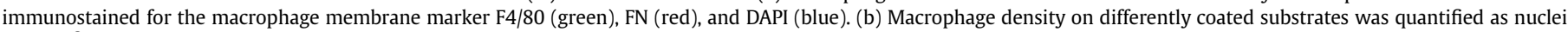

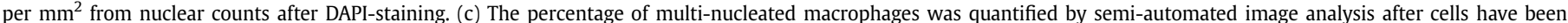

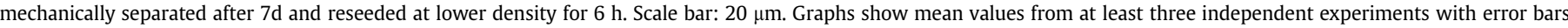

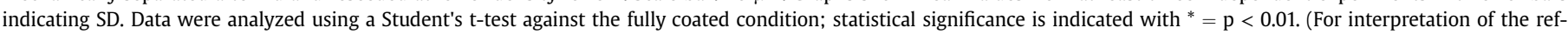
erences to colour in this figure legend, the reader is referred to the web version of this article.)

evaluate whether this anti-fibrotic effect is relevant in vivo, we subcutaneously implanted respectively coated/patterned silicone strips subcutaneously to the dorsum of rats. As protein we used collagen type I that is available in medical grade due to its weak antigenicity and immunogenicity [26]. Uncoated silicone substrates were used to represent the current clinical standard for implant coating, and completely collagen coated silicone implants served as positive experimental controls. When the body reaction to protein patterned implants was histologically analyzed after 30 days (Fig. 7a), accumulation of ECM and cells around micro-patterned implants was substantially lower than in uncoated and fully coated controls (Fig. $7 \mathrm{~b}-\mathrm{d}$ ). The center of capsules formed around uncoated silicone implants was particularly rich in multi-nucleated cells (6-fold compared to both other groups) which were identified as foreign-body giant cells (Fig. $7 \mathrm{~b}$, inset) that stained positive for the macrophage marker CD68 (Fig. 8a, green, arrows). Multinucleated giant cells were virtually absent from capsules forming around micro-patterned and fully coated implants (Fig. 7b) with only few CD68-positive macrophages localizing to the implant-tissue interface (Fig. 8a, green, arrows). The collagenous ECM organization and cellularity of capsules formed around micropatterned capsules was morphologically similar to the adjacent normal connective tissue (Fig. 7a, b). In contrast, collagen coated and uncoated implants were characterized by accumulation of dense ECM fibers and high cell density (Fig. 7b). To quantify the thickness of the collagenous capsule wall surrounding the implant we performed morphometric image analysis on cross-sections of excised capsules with associated tissue that were stained with Masson's Trichrome (Fig. 7c). The capsule wall diameter around micro-patterned implants $(37 \pm 10 \mu \mathrm{m})$ was 3-times smaller than the collagen rich layer around uncoated implants $(50 \pm 19 \mu \mathrm{m})$ and 1.5 -times smaller than around fully coated implants $(90 \pm 37 \mu \mathrm{m})$ (Fig. 7c).

Collagenous capsules always form around implants to various degrees; it is the accumulation of contractile myofibroblasts that ultimately leads to ECM contracture and necessitates recurrent surgery $[27,28]$. Immunostaining of tissue cross-sections for $\alpha$-SMA revealed that myofibroblasts accumulated to different degrees depending on the implant coating, being lowest in the micropatterned group (Fig. 8a). To quantify myofibroblast occurrence, cross-sections were immunohistochemically stained for $\alpha$-SMA and the thickness of the $\alpha$-SMA-positive layer was measured from the implant surface (Fig. 7d). The $\alpha$-SMA positive layer at the surface of micro-patterned implants was significantly thinner $(20 \pm 7 \mu \mathrm{m})$ than around completely coated implants $(45 \pm 18 \mu \mathrm{m})$ and uncoated implants $(50 \pm 21 \mu \mathrm{m})$ (Fig. 7d). This layer comprised almost $90 \%$ of the total wall thickness around completely coated implants but only $\sim 50 \%$ of the capsule wall around micro-patterned and uncoated implants. Analyzing the staining intensities of collagen and $\alpha$-SMA delivered similar results than those obtained from measuring layer thickness (Fig. 8b). Collagen density in the capsule was $\sim 2$-times lower $(20 \pm 4 \%$ ) compared with capsules formed around completely coated silicone $(46.3 \pm 19 \%)$ and $~ 3-$ times lower than non-coated silicone implants $(62.7 \pm 15 \%)$ (Fig. 8b). The density of $\alpha$-SMA at the surface of micro-patterned implants was generally low $(22.3 \pm 8 \%)$, in contrast to the capsules of completely coated implants $(46.6 \pm 6 \%)$ and non-coated implants (56 15\%). Collagen and $\alpha$-SMA densities in the capsule layer were plotted against each other to provide a 'capsule contracture index' (Fig. 8 b) to show that $4 \times 2 \mu \mathrm{m}$ micropattern significantly reduce capsule formation and accumulation of contractile myofibroblasts in vivo.

\section{Discussion}

A variety of different medical implants are produced with a shell that is impermeable to cells, most often silicone or polyurethane, which comes into contact with the patient's host tissue. Since adverse reactions to silicone arise at the implant surface, recent fundamental and clinical research focus on silicone shell engineering to improve implant biointegration. In our study, we developed a novel protein micropattern coating that improved silicone implant biointegration by promoting: 1) decreased inflammatory foreign body reaction, 2 ) controlled cell and fibroblast adhesion, and 3 ) decreased activation of $\alpha$-SMA-positive myofibroblasts (Fig. 9).

The formation of collagen-rich capsules around implants is part of the normal wound healing response of inflammation, cell proliferation, and tissue remodeling [3]. Material charge, wettability, and topographic structure have a substantial impact on the adhesive properties of silicone implants [29]. If implant materials are non-adhesive for host cells and ECM, dead space develops between the tissue and the implant surface, allowing non-specific absorption of blood plasma and serum proteins [3]. This chemical microenvironment attracts and activates macrophages as important sources of pro-fibrotic cytokines, leading to fibroblast recruitment and myofibroblast activation [30]. Conversely, adhesive implants appear to partially reduce macrophage activation and fusion into multi-nucleated giant cells during the foreign body reaction [29]. Consistently, low-adhesive untreated silicones in our 

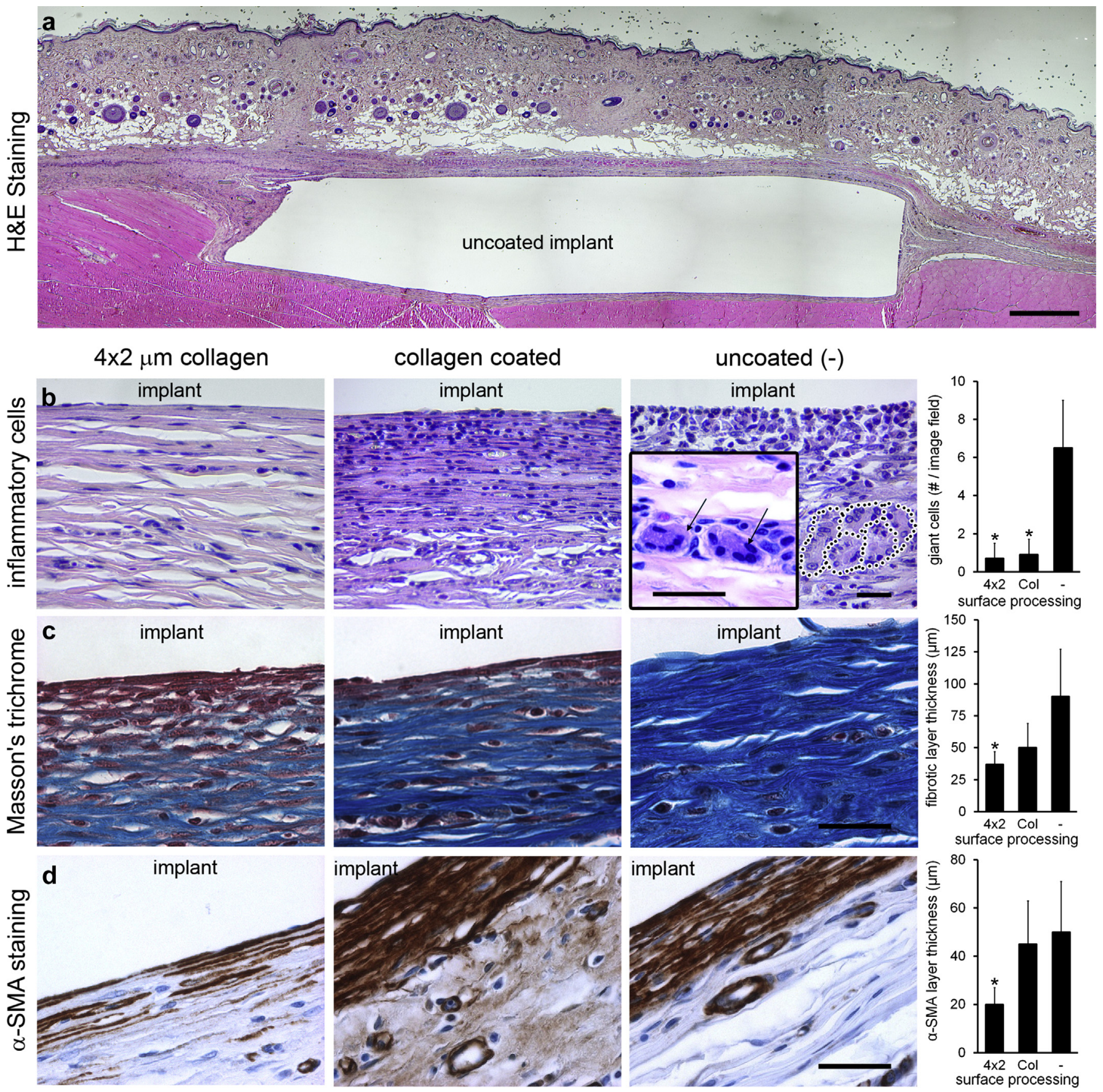

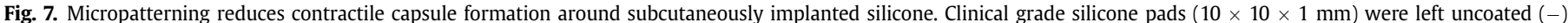

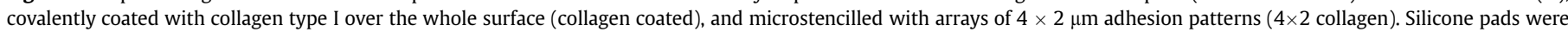

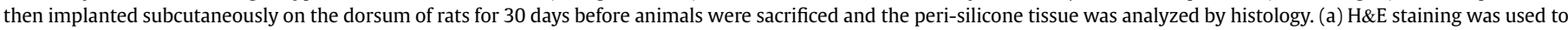

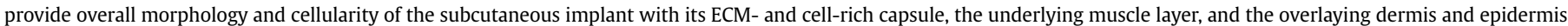

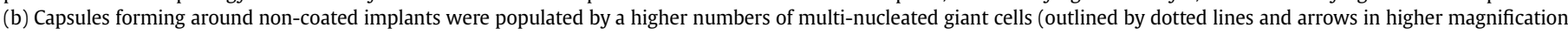

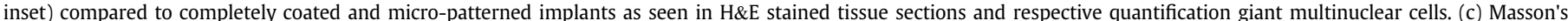

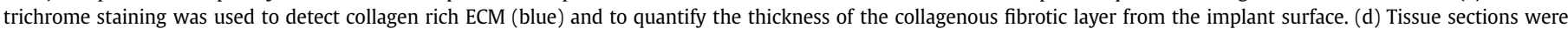

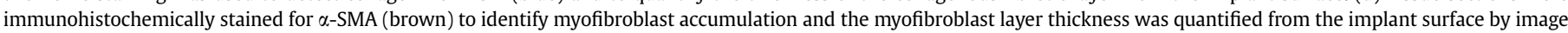

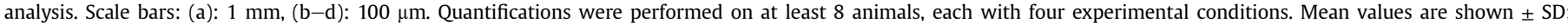
${ }^{*} \mathrm{p} \leq 0.01$, two-tailed paired Student's t-test.

study produced higher numbers of multi-nucleated giant cells compared to adhesive fully coated substrates in vivo and in vitro. It is currently unclear, how $4 \times 2$ micro-patterned silicone surfaces further suppress giant cell formation to $\sim 20 \%$ of fully coated silicone. However, other studies have shown that dictating macrophage shape and spreading by controlling substrate topography is able to control the activation state of macrophages [31,32].

Despite reducing the macrophage-dominated foreign-body reaction, highly adhesive silicone surfaces, such as the fully protein coated silicones in our study, trigger severe fibrotic capsule 
a
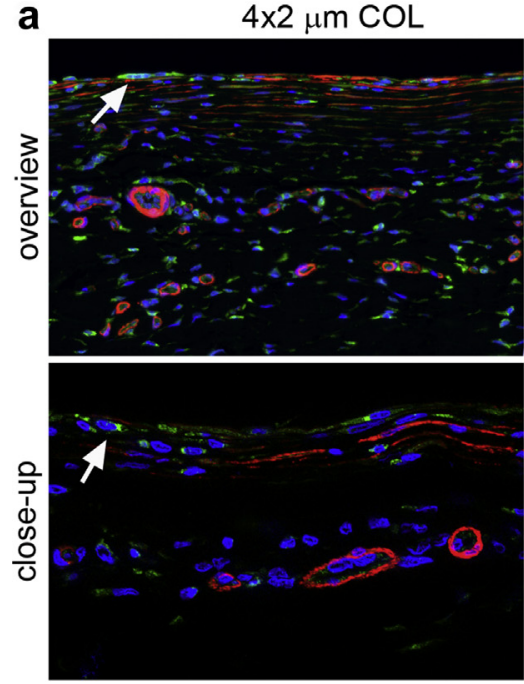

b

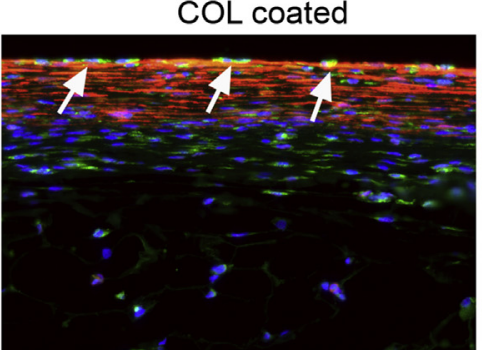

COL coated

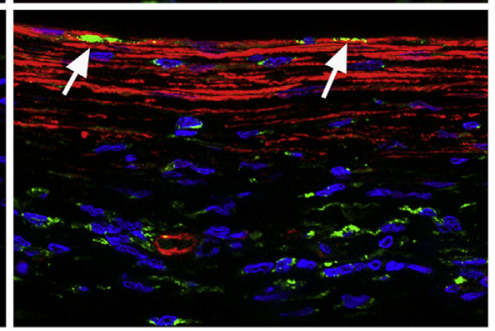

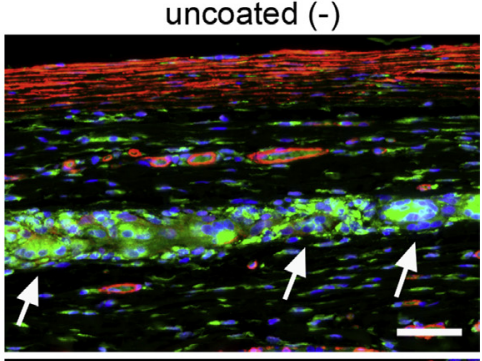

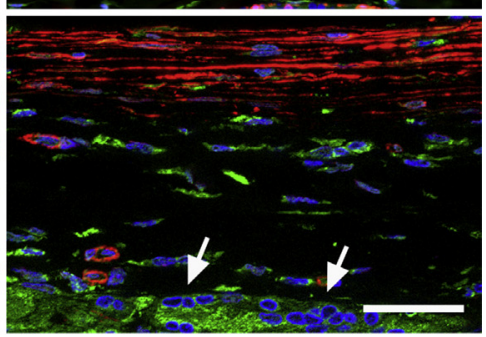

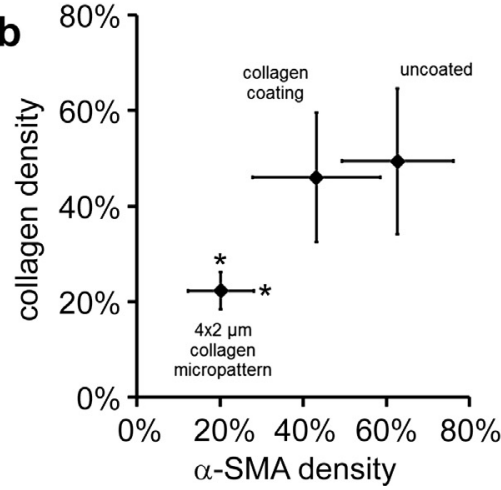

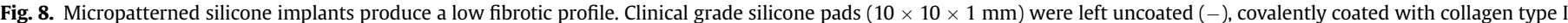

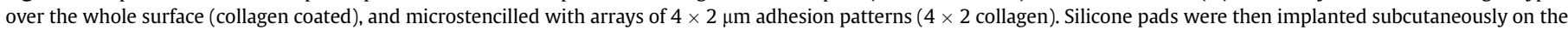

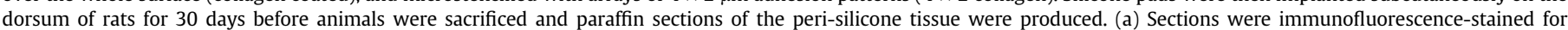

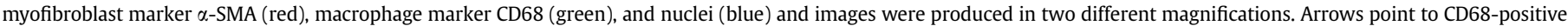

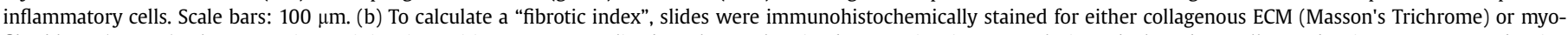

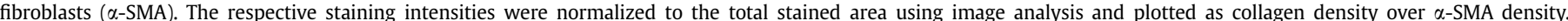

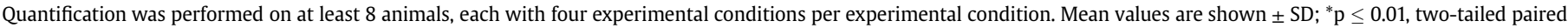
Student's t-test.

formation and contracture [23]. In these conditions, activation of myofibroblasts is the main driver for fibrogenesis and can occur even at reduced levels of inflammation. A plethora of studies demonstrated the spontaneous activation of various precursor cells to attain the myofibroblast phenotype on pathophysiologically stiff polymer substrates [18,33-36]. Despite being macroscopically deformable, implant silicone materials have a 100-1000-times higher elastic modulus $(\sim 500-3000 \mathrm{kPa})$ than the connective tissue of of recipient tissues like skin dermis [37,38] $(\sim 0.5-5 \mathrm{kPa})$. Myofibroblast activation is effectively suppressed by reducing mechanical stress, either acting as extracellular stress in tissue strain and stiffness or intracellularly as cell contraction [11]. Development of intracellular stress is limited by the amount of force that fibroblasts can transmit to any material, which can be modulated by controlling substrate adhesiveness, deformability (elastic modulus), or topography to promote cell spreading [36,39-41]. In a previous study, we have shown that controlling the size of individual FAs, i.e. the efficacy of cell mechanosensing and force transmission, controls intracellular stress and myofibroblast activation [17]. This effect was largely independent from island density as shown by modulating island spacing from 2 to $6 \mu \mathrm{m}$. However, a regular arrangement of FAs is pivotal because fibroblasts are able to extend single FAs over multiple small islands that are closer than $\sim 1.5 \mu \mathrm{m}$ and accommodate cell morphology to exert maximum tension. The size of FAs is linearly related to the force they can transmit and sustain with a stress of $\sim 5.5 \mathrm{nN} / \mu \mathrm{m}^{2}$ for classical FAs and $\sim 12.5 \mathrm{nN} / \mu \mathrm{m}^{2}$ for myofibroblast supermature FAs $[17,42]$. Hence, restricting FAs size by micropatterning will limit the tension developed by stress fibers that are anchored to the ECM at FAs. We have previously shown that high intracellular stress, in turn, is required to promote myofibroblast activation and incorporation of $\boldsymbol{\alpha}$-SMA into stress fibers [17,21,37]. Once myofibroblasts are formed, they will contribute to collagen accumulation and fibrotic capsule contraction around the implant. For the present study, we have selected micropattern arrays of $4 \times 2 \mu \mathrm{m}$ sized adhesive structures that were shown to arrest fibroblasts in a noncontractile, non-fibrotic state even on GPa-stiff plastic and glass surfaces [17]. Transfer of these patterns to silicone implants was sufficient to supress myofibroblast activation by 2-3-fold compared to fully protein coated silicone pro-fibrotic conditions in culture and animal experiments.

Generation of protein patterns with micron-resolution on glass and plastic is effective using microcontact printing [43-45]. However, to achieve good transfer, protein adhesion to the silicone 


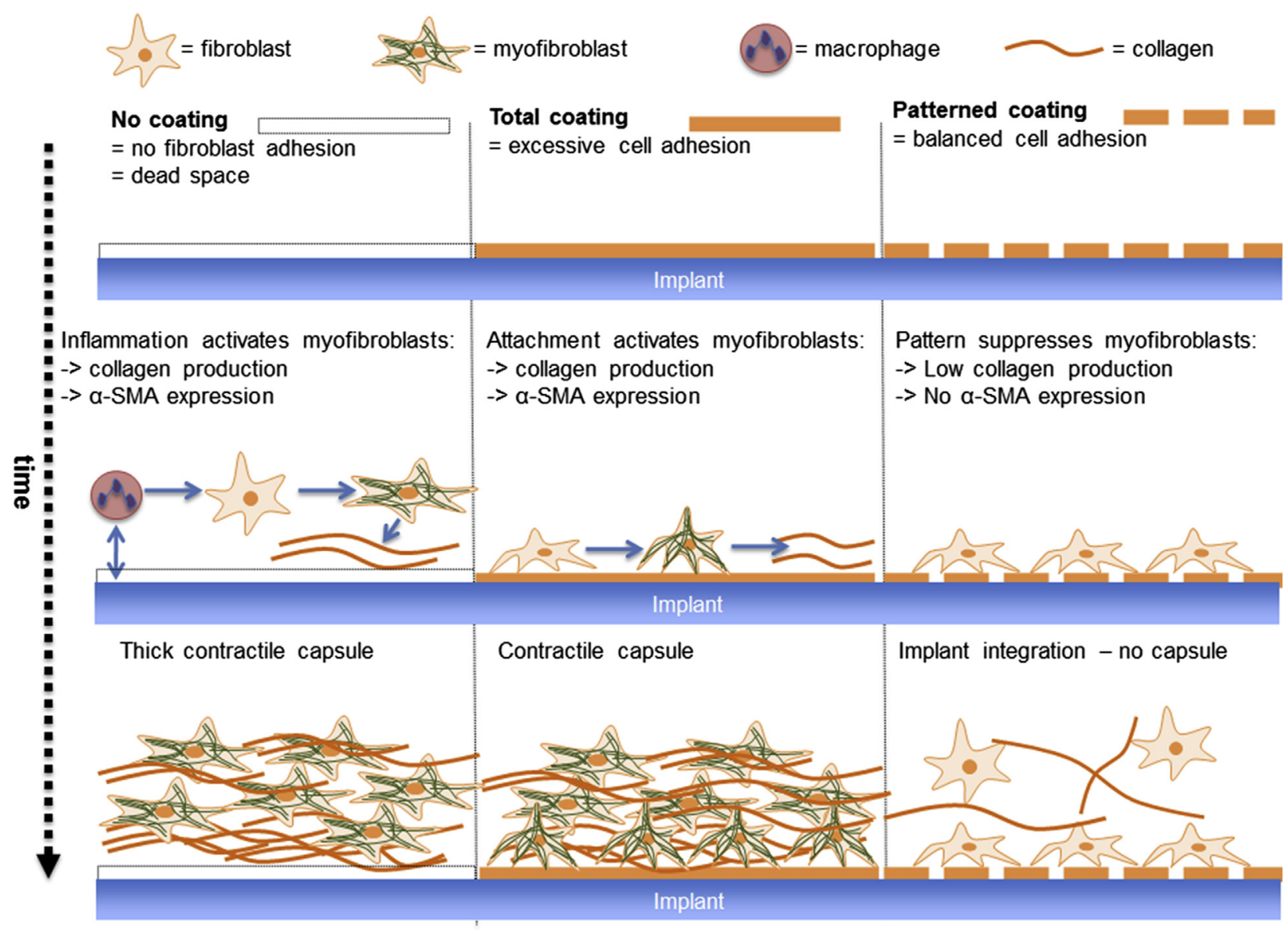

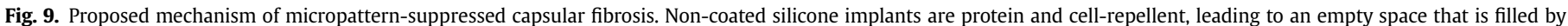

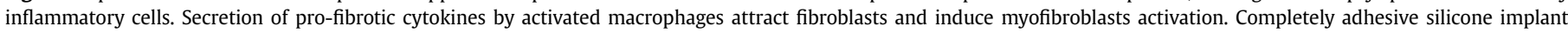

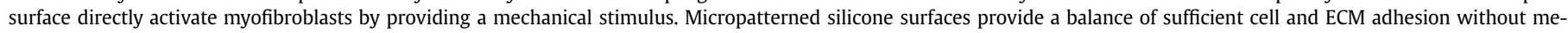
chanically activating fibroblastic and inflammatory cells resulting in a reduced capsule thickness.

rubber stamp has to be lower than the affinity to the substrate. This is difficult to achieve when both substrate and stamp are fabricated with the same silicone material and similar mechanical properties. We here solved this critical limitation of former techniques by developing an innovative microstencil method to covalently attach soluble adhesive compounds, including proteins onto silicone substrates with $\sim 1 \mu \mathrm{m}$ resolution. Using pliable pyrelene stencils, we are further able accommodate curved and three-dimensionally complex surfaces. One open remaining question is whether the anti-fibrotic effect of the novel micropattern observed after 1 week in culture and after 4 weeks in animal experiments will last in longterm clinical applications. Preliminary results at one year show a stable tissue reaction around the implants (not shown) and a number of studies suggest that early activation of myofibroblasts already sets the stage for a persistent fibrotic reaction. This effect is partly due to the specific chemical and mechanical property of myofibroblast-derived ECM $[46,47]$ and partly due to the ability of myofibroblast populations to retain and propagate once acquired features in a changed environment [48].

In summary, our results suggest that uncoated silicone induces the formation of a fibrotic capsule containing a high number of contractile myofibroblasts, probably as a result of lack of cell adhesion and macrophage activation via foreign body reaction. Completely coated silicone surfaces have similar fibrotic effects because unrestricted cell attachment sites cause high myofibroblast development possibly via intracellular mechanical forces development on the implant surface during healing. The identified novel methods to generate micropatterns on silicone substrates suppressed the dead space and decreased foreign body reaction, while also having an anti-fibrotic effect due to the specific design $(4 \times 2 \mu \mathrm{m})$ of the adhesion sites.

\section{Conclusions}

In conclusion, we have developed a novel strategy to make silicone surfaces more biocompatible. This micro-patterning approach has several advantages compared to previously proposed techniques including the possibility to being applied to several different biomaterials without changing their macroscopic properties and being based entirely on clinically used substrates. These experimental results will hopefully set the stage for clinical translation in the near future.

\section{Acknowledgments}

Dr. G. Gabbiani is acknowledged for providing antibodies. The authors thank Drs. Enrico Vigato, Ilaria Tocco, Philippe Renaud, Jürgen Brugger, and Ruud Bank for discussions, and technical and intellectual support. We thank the staff of the center of MicroNanotechnology (EPFL) for outstanding technical help. Marine Polymer Technologies, Danvers, MA is acknowledged for donating Poly-N-Acetyl Glucosamine for the experiments. The project was funded by the Swiss Commission for Technology and Innovation, CTI Discovery Project N. 10447.1 PFLS-LS (to GP, HM and BH), the 
Gebert Rüf Stiftung grant \#GRS-012/05 (to BH), Switzerland and by the Competence Centre for Materials Science and Technology (CCMX) of the ETH-Board (to BH). Additional funding was obtained from the Canadian Institutes of Health Research (CIHR grants \#210820, \#286720, and \#137060), the Collaborative Health Research Program (CIHR/NSERC) grant \#1004005, and the Canada Foundation for Innovation (CFI) and Ontario Research Fund (ORF) (grant \#26653) (all to $\mathrm{BH}$ ) and the Fond National Suisse (grant \#310030_120571) to BP.

\section{Appendix A. Supplementary data}

Supplementary data related to this article can be found online at http://dx.doi.org/10.1016/j.biomaterials.2015.03.027.

\section{References}

[1] Prokop A. Bioartificial organs in the twenty-first century: nanobiological devices. Ann N. Y Acad Sci 2001;944:472-90. Epub 2002/01/19.

[2] Araco A, Caruso R, Araco F, Overton J, Gravante G. Capsular contractures: systematic review. Plast Reconstr Surg 2009;124(6):1808-19. Epub 2009/12/ 03.

[3] Anderson JM, Rodriguez A, Chang DT. Foreign body reaction to biomaterials. Semin Immunol 2008:20(2):86-100.

[4] Suska F, Emanuelsson L, Johansson A, Tengvall P, Thomsen P. Fibrous capsule formation around titanium and copper. J Biomed Mater Res A 2008;85(4): 888-96.

[5] Mase H, Tamura K, Hiromoto A, Hotta M, Hotomi S, Togashi M, et al. Histopathological study of tissue reaction to pacemaker electrodes implanted in the endocardium. J Nippon Med Sch 2005;72(1):52-9. Epub 2005/04/19.

[6] Rizzello V, Dello Russo A, Casella M, Biddau R. Residual fibrous tissue floating in the right atrium after percutaneous pacemaker lead extraction: an unusual complication early detected by intracardiac echocardiography. Int J Cardiol 2008:127(2):e67-8. Epub 2007/06/26.

[7] Moore KB, Saudek CD, Greene A, Dackiw A. Implantable insulin pump therapy: an unusual presentation of a catheter-related complication. Diabetes Technol Ther 2006;8(3):397-401. Epub 2006/06/28.

[8] Pashuck ET, Stevens MM. Designing regenerative biomaterial therapies for the clinic. Sci Transl Med 2012;4(160):160sr4. Epub 2012/11/16.

[9] Williams DF. Tissue - biomaterial interactions. J Mater Sci 1987;22(10): $3421-45$

[10] Martino MM, Tortelli F, Mochizuki M, Traub S, Ben-David D, Kuhn GA, et al. Engineering the growth factor microenvironment with fibronectin domains to promote wound and bone tissue healing. Sci Transl Med 2011;3(100): 100ra89. Epub 2011/09/16.

[11] Hinz B. The myofibroblast: paradigm for a mechanically active cell. J Biomech 2010;43(1):146-55. Epub 2009/10/06.

[12] Hinz B, Dugina V, Ballestrem C, Wehrle-Haller B, Chaponnier C. Alpha-smooth muscle actin is crucial for focal adhesion maturation in myofibroblasts. Mol Biol Cell 2003;14(6):2508-19.

[13] Geiger B, Spatz JP, Bershadsky AD. Environmental sensing through focal adhesions. Nat Rev Mol Cell Biol 2009:10(1):21-33. Epub 2009/02/07.

[14] Wehrle-Haller B. Assembly and disassembly of cell matrix adhesions. Curr Opin Cell Biol 2012;24(5):569-81. Epub 2012/07/24.

[15] Roca-Cusachs P, Iskratsch T, Sheetz MP. Finding the weakest link: exploring integrin-mediated mechanical molecular pathways. J Cell Sci 2012;125(Pt 13): 3025-38. Epub 2012/07/17.

[16] Barr S, Bayat A. Breast implant surface development: perspectives on development and manufacture. Aesthet Surg J 2011;31(1):56-67. Epub 2011/ $01 / 18$.

[17] Goffin JM, Pittet P, Csucs G, Lussi JW, Meister JJ, Hinz B. Focal adhesion size controls tension-dependent recruitment of alpha-smooth muscle actin to stress fibers. J Cell Biol 2006;172(2):259-68.

[18] Wipff PJ, Rifkin DB, Meister JJ, Hinz B. Myofibroblast contraction activates latent TGF-beta1 from the extracellular matrix. J Cell Biol 2007;179(6): 1311-23. Epub 2007/12/19.

[19] Wipff PJ, Majd H, Acharya C, Buscemi L, Meister JJ, Hinz B. The covalent attachment of adhesion molecules to silicone membranes for cell stretching applications. Biomaterials 2009;30(9):1781-9. Epub 2008/12/30.

[20] Majd H, Quinn TM, Wipff PJ, Hinz B. Dynamic expansion culture for mesenchymal stem cells. Methods Mol Biol 2011;698:175-88. Epub 2011/03/25.
[21] Modarressi A, Pietramaggiori G, Godbout C, Vigato E, Pittet B, Hinz B. Hypoxia impairs skin myofibroblast differentiation and function. J Invest Dermatol 2010;130(12):2818-27. Epub 2010/08/06.

[22] Scherer SS, Tobalem M, Vigato E, Heit Y, Modarressi A, Hinz B, et al. Nonactivated versus thrombin-activated platelets on wound healing and fibroblastto-myofibroblast differentiation in vivo and in vitro. Plast Reconstr Surg 2012;129(1):46e-54e. Epub 2011/12/22.

[23] Franz S, Rammelt S, Scharnweber D, Simon JC. Immune responses to implants - a review of the implications for the design of immunomodulatory biomaterials. Biomaterials 2011;32(28):6692-709. Epub 2011/07/01.

[24] Potter EH, Rohrich RJ, Bolden KM. The role of silicone granulomas in recurrent capsular contracture: a review of the literature and an approach to management. Plast Reconstr Surg 2013;131(6):888e-95e. Epub 2013/05/30.

[25] McNally AK, Anderson JM. Macrophage fusion and multinucleated giant cells of inflammation. Adv Exp Med Biol 2011;713:97-111. Epub 2011/03/25.

[26] Lynn AK, Yannas IV, Bonfield W. Antigenicity and immunogenicity of collagen. J Biomed Mater Res B Appl Biomater 2004;71(2):343-54. Epub 2004/09/24.

[27] Coleman DJ, Sharpe DT, Naylor IL, Chander CL, Cross SE. The role of the contractile fibroblast in the capsules around tissue expanders and implants. Br J Plast Surg 1993;46(7):547-56.

[28] Baker Jr JL, Chandler ML, LeVier RR. Occurrence and activity of myofibroblasts in human capsular tissue surrounding mammary implants. Plast Reconstr Surg 1981;68(6):905-12. Epub 1981/12/01.

[29] Wilson CJ, Clegg RE, Leavesley DI, Pearcy MJ. Mediation of biomaterial-cell interactions by adsorbed proteins: a review. Tissue Eng 2005;11(1-2):1-18. Epub 2005/03/02.

[30] Wynn TA, Ramalingam TR. Mechanisms of fibrosis: therapeutic translation for fibrotic disease. Nat Med 2012;18(7):1028-40. Epub 2012/07/10.

[31] Ghrebi S, Hamilton DW, Douglas Waterfield J, Brunette DM. The effect of surface topography on cell shape and early ERK1/2 signaling in macrophages; linkage with FAK and Src. J Biomed Mater Res A 2013;101(7):2118-28. Epub 2013/02/22.

[32] McWhorter FY, Wang T, Nguyen P, Chung T, Liu WF. Modulation of macrophage phenotype by cell shape. Proc Natl Acad Sci U.S.A 2013;110(43): 17253-8. Epub 2013/10/09.

[33] Li Z, Dranoff JA, Chan EP, Uemura M, Sevigny J, Wells RG. Transforming growth factor-beta and substrate stiffness regulate portal fibroblast activation in culture. Hepatology 2007;46(4):1246-56.

[34] Olsen AL, Bloomer SA, Chan EP, Gaca MD, Georges PC, Sackey B, et al. Hepatic stellate cells require a stiff environment for myofibroblastic differentiation. Am J Physiol Gastrointest Liver Physiol 2011;301(1):G110-8. Epub 2011/04/30.

[35] Huang X, Yang N, Fiore VF, Barker TH, Sun Y, Morris SW, et al. Matrix stiffnessinduced myofibroblast differentiation is mediated by intrinsic mechanotransduction. Am J Respir Cell Mol Biol 2012;47:340-8.

[36] MacQueen L, Sun Y, Simmons CA. Mesenchymal stem cell mechanobiology and emerging experimental platforms. J R Soc Interface 2013;10(84): 20130179. Epub 2013/05/03.

[37] Achterberg VF, Buscemi L, Diekmann H, Smith-Clerc J, Schwengler H, Meister JJ, et al. The nano-scale mechanical properties of the extracellular matrix regulate dermal fibroblast function. J Invest Dermatol 2014;134(7): 1862-72. Epub 2014/03/29.

[38] Samani A, Zubovits J, Plewes D. Elastic moduli of normal and pathological human breast tissues: an inversion-technique-based investigation of 169 samples. Phys Med Biol 2007;52(6):1565-76. Epub 2007/03/01.

[39] Janmey PA, Wells RG, Assoian RK, McCulloch CA. From tissue mechanics to transcription factors. Differentiation 2013:86(3):112-20. Epub 2013/08/24.

[40] Mammoto A, Ingber DE. Cytoskeletal control of growth and cell fate switching. Curr Opin Cell Biol 2009;21(6):864-70. Epub 2009/09/11.

[41] Godbout C, Follonier Castella L, Smith EA, Talele N, Chow ML, Garonna A, et al. The mechanical environment modulates intracellular calcium oscillation activities of myofibroblasts. PLoS One 2013;8(5):e64560. Epub 2013/05/22.

[42] Balaban NQ. Force and focal adhesion assembly: a close relationship studied using elastic micropatterned substrates. Nat Cell Biol 2001:3:466-72.

[43] Csucs G, Michel R, Lussi JW, Textor M, Danuser G. Microcontact printing of novel co-polymers in combination with proteins for cell-biological applications. Biomaterials 2003:24(10):1713-20.

[44] Singhvi R, Kumar A, Lopez GP, Stephanopoulos GN, Wang DIC, Whitesides GM, et al. Engineering cell shape and function. Science 1994;264:696-8.

[45] Whitesides GM, Ostuni E, Takayama S, Jiang X, Ingber DE. Soft lithography in biology and biochemistry. Annu Rev Biomed Eng 2001:3:335-73.

[46] Klingberg F, Hinz B, White ES. The myofibroblast matrix: implications for tissue repair and fibrosis. J Pathol 2013;229(2):298-309. Epub 2012/09/22.

[47] Parker MW, Rossi D, Peterson M, Smith K, Sikstrom K, White ES, et al. Fibrotic extracellular matrix activates a profibrotic positive feedback loop. I Clin Invest 2014; $124: 1622-35$.

[48] Balestrini JL, Chaudhry S, Sarrazy V, Koehler A, Hinz B. The mechanical memory of lung myofibroblasts. Integr Biol (Camb) 2012;4(4):410-21. Epub $2012 / 03 / 14$ 